\title{
LAS DESTREZAS NARRATIVAS EN NIÑOS DE 5 AÑOS: PROPUESTA DE UN INSTRUMENTO DE EVALUACIÓN CLÍNICA DEL LENGUAJE
}

\section{NARRATIVE SKILLS IN FIVE-YEAR-OLD CHILDREN: DESIGN OF AN INSTRUMENT FOR CLINICAL ASSESSMENT OF LANGUAGE}

\author{
María Del Valle Abraham ${ }^{1}$ \\ Rosa María Brenca ${ }^{1}$ \\ Valeria Guaita ${ }^{2}$ \\ ${ }^{1}$ Hospital Italiano de Buenos Aires, Servicio de ORL- Sector Lenguaje \\ ${ }^{2}$ Centro Interdisciplinario de Investigación de Psicología y Matemática Experimental - CONICET \\ Correspondencia a: maria.abraham@hospitalitaliano.org.ar
}

\begin{abstract}
RESUMEN
Las habilidades implicadas en la competencia narrativa permiten predecir el futuro desempeño lingüísticocognitivo del niño, por lo cual resulta fundamental contar con recursos evaluativos específicos en la clínica fonoaudiológica. Proponemos un instrumento de evaluación de tales destrezas infantiles que abarca tanto las habilidades correspondientes al desarrollo de la estructura narrativa canónica como las que corresponden a la expresión del contenido, cuyas características se analizan mediante la actividad de renarración de un cuento con imágenes, creado ad hoc. Los datos se registran en un formulario diseñado para el análisis sistemático cuanti- cualitativo. Se presentan los materiales empleados y el análisis psicométrico preliminar, realizado en un estudio piloto con 22 niños preescolares sin problemas de lenguaje, de clase media, de la ciudad de Buenos Aires. Los resultados reflejan la fortaleza del instrumento para establecer, con precisión, cuáles son las destrezas narrativas en la edad preescolar y el modo de evaluarlas.
\end{abstract}

Palabras clave: Competencia narrativa infantil, renarración, evaluación fonoaudiológica.

\begin{abstract}
The skills involved in narrative competence allow us to predict the child's further cognitive-linguistic performance. Thus, from a speech and language perspective, it is extremely important to have clinical tools to evaluate such aspect ,. The present manuscript addresses the design of a clinical instrument to assess the abilities involved in narrative competence. Such abilities comprise those related to the development of canonical narrative structure as well as those related to the expression of content. These abilities are analysed through an activity of re-telling a story induced from an ad-hoc oral text accompanied with pictures. A form specifically created for systematic qualitative and quantitative analysis was used to collect the data. The materials used in and a preliminary psychometric analysis of a pilot study conducted in 22 normal-language development pre-school children coming from middle-class families in the city of Buenos Aires are discussed. The results show that the instrument is capable of determining which narrative skills are involved in pre-school children and the manner they should be assessed.
\end{abstract}

Key words: Children's narrative competence, retelling, language assessment. 


\section{INTRODUCCIÓN}

En trabajos anteriores las autoras han propuesto el análisis y evaluación de la comunicación preverbal, así como, y fundamentalmente, de los actos de habla en tanto unidades mínimas de la comunicación, en niños de edad preescolar ${ }^{(1-3)}$. Precisamente, la secuencia de actos de habla constituye el discurso.

Con referencia al lenguaje infantil, es de interés, en particular, el discurso narrativo, debido a su importancia para predecir el futuro desempeño lingüístico-cognitivo del niño ${ }^{(4-7)}$. "Construir historias en la mente [...] es uno de los medios más fundamentales de construir significado, y como tal, es una actividad que domina todos los aspectos del aprendizaje"(8). Por lo tanto, nos proponemos enfatizar la importancia del estudio de las destrezas narrativas en el mencionado grupo etáreo, y su particular tratamiento en los niños con trastornos del lenguaje.

\section{Importancia de la narración}

"El relato está presente en todas las épocas, en todo lugar, en todas las sociedades; el relato comienza con la historia misma de la humanidad"(9).

En las sociedades sin escritura, las explicaciones sobre el origen del mundo en general y del hombre en particular son los mitos originarios que se trasmiten mediante narraciones orales, de generación en generación, y permiten interpretar las experiencias inexplicables.

En las sociedades letradas, las teorías científicas que cumplen ese fin son también, en última instancia, narraciones. La historia es la gran narración del ser humano. No existe ninguna comunidad humana sin narraciones, porque la forma narrativa es el modo fundamental de la actividad de la mente en la comunicación interhumana ${ }^{(10)}$. Aparece en el lenguaje de la interacción social cotidiana, en la escuela y en el entretenimiento: la literatura, el cine y la televisión.

Desde su nacimiento, los niños van integrándose a la cultura de su comunidad gracias a las narraciones que pululan a su alrededor y los ayudan a construir los marcos lingüísticos y sociales que les permitirán interpretar los enunciados de los demás. Alrededor de los 2 años, esta actividad comienza a hacerse consciente y a practicarse de modo rudimentario, con la importante ayuda de los adultos. De esta manera, los niños irán integrando los valores y la 
lengua de su cultura. Entre los 4 y 5 años, la narración aparece en el juego dramático para crear el marco de la acción compartida y estructurar el mundo imaginario(8).

Bruner ${ }^{(10)}$ dedica un libro a esta actividad, La Fábrica de Historias (2003), y lo comienza diciendo: "Somos tan buenos para relatar que esta facultad parece casi tan natural como el lenguaje. Inclusive modelamos nuestros relatos sin ningún esfuerzo, con el objeto de adaptarlos a nuestros fines (comenzando por las pequeñas argucias para echarle la culpa a nuestro hermanito menor por la leche derramada) [...]. Nuestro uso frecuente de los relatos comienza temprano en nuestra vida y prosigue sin detenciones; no maravilla que sepamos cómo tratarlos".

En efecto, si el contacto con las narraciones comienza temprano en la vida de un niño, y éste no presenta trastornos en su desarrollo, no hay duda que será capaz de comprenderlas y también de relatar sus experiencias reales y sus fantasías, así como de asimilar fácilmente las narraciones propias de la instrucción escolar.

Por ello, el dominio del relato, en un niño, constituye un dato que hay que tener en cuenta para evaluar su desarrollo cognitivo y lingüístico, y de ahí la importancia de evaluar las destrezas narrativas alrededor de los 5 años, edad en que la representación cognitiva orienta la estructuración de la información lingüística percibida ${ }^{(11,12)}$.

\section{La competencia narrativa}

Paul et al ${ }^{(13)}$ la sintetizan de esta manera: "La habilidad para contar un cuento implica una cantidad de destrezas cognitivas y lingüísticas de nivel más alto. Incluyen la habilidad para secuenciar eventos, para crear un texto cohesivo mediante el uso de marcadores lingüísticos explícitos, para usar un vocabulario preciso, trasmitir ideas sin soporte extralingüístico, comprender las relaciones de causa-efecto, y estructurar la narración según las líneas del esquema universal del relato que ayuda al oyente a comprender la historia".

La narración oral participa de algunas características del lenguaje escrito que la convierten en un puente entre la oralidad y la escritura ${ }^{(7,13)}$. Una de esas características es la descontextualización ${ }^{(14)}$, que obliga a explicitar el lugar y el tiempo de los sucesos narrados, que no son los del momento en que se produce el relato. El que narra (incluso cuando se refiere a sí mismo) se coloca en el lugar del espectador, y tiene conciencia de que refiere algo que ya ha ocurrido (real o ficticio), por lo cual usa tiempos verbales pretéritos (imperfecto y perfecto simple) en una secuencia tanto temporal como causal. 
Por otra parte, la actividad de narrar implica la previa selección y el ordenamiento de los hechos a los que se hace referencia, es decir, una macroestructura ${ }^{(15)}$ o plan global(16). Wells ${ }^{(8)}$, comentando el rol de espectador que Britton ${ }^{(17)}$ atribuye al narrador, explica que este papel nos libera de las exigencias que nos plantea una participación práctica en un evento y nos permite una actitud más reflexiva para descubrir la consistencia interna y la estructura de lo que se narra.

La consistencia interna depende de las relaciones de cohesión entre las oraciones, necesarias para que éstas constituyan un texto y no una hilera de oraciones. Entre las relaciones de cohesión, son fundamentales la causal y la espacial. La relación temporal, por su parte, está íntimamente relacionada con la causal, ya que, según dice Kant en su Crítica de la Razón Pura, ${ }^{(18)}$ la ley de causalidad establece que "Todos los cambios acontecen según la ley del enlace de causas y efectos [...]. Sólo porque sometemos la sucesión de fenómenos [...] a la ley de causalidad, es posible la experiencia", de lo cual se infiere que la noción de causalidad es imprescindible para el aprendizaje.

En cuanto a la relación espacial, Mandler ${ }^{(19)}$ sugiere que "la mayoría de los significados básicos que expresa la lengua (tanto semánticos como sintácticos) se basan en representaciones espaciales", y que "el lenguaje está estructurado con relevancia de lo espacial porque el sistema de significados en el aprendizaje del lenguaje preverbal está estructurado espacialmente". Agrega que los bebés son capaces de abstraer regularidades espaciales que formarán los primeros significados de conceptos.

Todo lo planteado hasta aquí es en cuanto a la consistencia interna del relato, que corresponde al contenido. El otro aspecto es el de la estructura.

La estructura narrativa responde a un canon tradicional, de acuerdo con una de las dos modalidades con que funciona la mente humana, que es la del relato. La otra es la lógica, que se aplica en la ciencia(20).

Un cuento o relato comienza con una situación inicial de equilibrio, que termina cuando se produce la acción desencadenante de la historia. Esta acción conduce al surgimiento del problema, a cuya solución se arribará a través de distintas peripecias. La habilidad del niño para comprender y producir una narración que cumpla con estos requisitos constituye un factor fundamental en el desarrollo cognitivo y, por lo tanto, merece consideración especial en la práctica clínica. 
El estudio de la competencia narrativa tiene numerosos antecedentes, que presentan distintas modalidades con resultados diversos, tanto en el estudio del lenguaje espontáneo como de la re-narración.

Hay discusiones acerca del estímulo adecuado para elicitar una narración: un estímulo exclusivamente oral, o exclusivamente visual o ambos combinados. Cuando se refieren al visual, se trata por lo general de films. Gibbons et al ${ }^{(21)}$ comprobaron que niños de 4 años demostraban mejor desempeño cuando reproducían cuentos que habían visto en video grabaciones (imágenes acompañadas de diálogo y narración), que cuando se había utilizado una grabación exclusivamente oral del mismo cuento. En cambio, Hayes et al ${ }^{(22)}$ observaron que niños de 3 a 6 años recordaban más diálogo pero cometían más errores de memoria, cuando escuchaban un cuento que cuando veían una versión animada de este mismo cuento acompañada por una versión oral. Schneider ${ }^{(12)}$ analiza el desempeño de niños con trastornos de lenguaje, de edades entre 5.07 y 9.09 , para comparar los resultados según los distintos estímulos, que consistían en la presentación de cuentos muy semejantes entre sí, de 4 modos diferentes a cada niño: solamente imágenes; presentación oral seguida por imágenes; presentación oral acompañada de imágenes; presentación exclusivamente oral.

En todos los casos, el investigador presentaba el cuento al niño y enseguida ingresaba al lugar un oyente que desconocía el cuento, y al cual se le impedía que viera las imágenes que el niño tenía delante. Los resultados indicaron que las re-narraciones elicitadas sólo con imágenes presentaban una estructura más simple, con episodios incompletos, más información nueva y menor confusión que las producidas tras una presentación oral. En cuanto a las presentaciones orales seguidas de imágenes, así como las simultáneas, en algunos casos elicitaron renarraciones inferiores a las obtenidas con la presentación exclusivamente oral. De todos modos, los autores, en general, admiten que las diversas edades y distintos niveles de los trastornos arrojan resultados diferentes.

Resulta de particular interés el trabajo de Paul y Smith ${ }^{(6)}$, quienes compararon las destrezas narrativas de niños de 4 años con desarrollo normal del lenguaje, con otros que presentaban retraso en el desarrollo, y con un tercer grupo que tenía trastornos del lenguaje. Recogieron datos del intercambio madre-hijo durante el juego, y luego emplearon el método de Renfrew "The bus story language test"(23). Este test se realiza con un cuento que trata acerca de un ómnibus desobediente. El evaluador se lo lee al niño mientras le muestra 12 láminas ilustrativas de la historia. Luego el niño produce su re-narración con las ilustraciones a la vista. Este estudio puso 
en evidencia la sensibilidad del instrumento y las ventajas del formato del test diseñado por Renfrew para evaluar la re-narración de niños preescolaresi.

Nuestro objetivo final es presentar un instrumento que permita evaluar la competencia narrativa de niños con trastornos del lenguaje, en la clínica fonoaudiológica. Para ello, es necesario contar, previamente, con datos sobre el rendimiento promedio esperable en niños sin trastornos del lenguaje, por lo cual resulta imprescindible disponer de un instrumento específico de evaluación.

Se presenta aquí la propuesta, expuesta en el X Congreso de ORL y Fonoaudiología Pediátrica (Buenos Aires, mayo 2008), con un material diseñado ad hoc. Se incluye el análisis psicométrico preliminar del instrumento, aplicado a una muestra piloto.

\section{MATERIAL Y MÉTODO}

En función de la revisión bibliográfica y de la experiencia clínica y lingüística de las autoras, se decidió emplear la actividad de re-narración de un cuento, que le brinda al niño el modelo de estructura, vocabulario y relaciones cohesivas, para analizar la competencia narrativa infantil. Este recurso nos permite realizar un análisis sistemático que no podríamos lograr mediante la narración espontánea, aunque ésta nos proporciona otro tipo de información importante que será tema de un futuro trabajo, complementario del presente.

Se considera, entonces, la re-narración como una herramienta útil en la evaluación clínica fonoaudiológica de niños que presentan trastornos del lenguaje. En consecuencia, se propuso, en primer lugar, diseñar un instrumento para analizar las destrezas narrativas de niños preescolares sin trastornos, cuyos puntajes, posteriormente, pudieran servir de parámetro en la evaluación clínica.

Para llegar a su aplicación en la patología, se ha planeado un proceso de 3 etapas con distintos objetivos, de los cuales el primero, ya alcanzado, constituye el tema de este trabajo:

Primera etapa: Diseño del instrumento para evaluar destrezas narrativas en niños preescolares. Toma de una prueba piloto y análisis psicométrico preliminar. Se realizó sobre un corpus de 22 
niños de 5 años a 6 años y 6 meses de edad, sin trastornos del lenguaje, que concurrían a un jardín de infantes privado, de clase media, de la Ciudad Autónoma de Buenos Aires.

Segunda etapa: Validación del instrumento: Análisis psicométrico de un corpus significativo con el mismo perfil.

Tercera etapa: Aplicación del instrumento para evaluar las destrezas narrativas en niños del mismo grupo etario con trastornos del lenguaje.

Los materiales fueron diseñados específicamente para la evaluación:

1- Cuento construido ad hoc, tanto el texto como las ilustraciones (Anexo 1), con las siguientes características:

- Texto de estructura canónica, con introducción, nudo y desenlace.

- Estilo lingüístico, estético y temático accesible a niños de edad preescolar.

- Imágenes diseñadas en color que ilustran el texto, con dibujos que propician la inferencia, ya que presentan elementos incompletos, "cortados" por el marco de la ilustración.

- Focalización del elemento relevante, en la imagen que corresponde a cada episodio.

2- $\quad$ La Hoja de Registro (Anexo 2). Diseñada para el análisis sistemático cuali-cuantitativo de la re-narración realizada por el niño. Los datos registrados están organizados en dos partes: una corresponde a la estructura y la otra, al contenido (consistencia interna). La hoja de registro está constituida por 22 ítems: 12 para medir la estructura narrativa canónica: ambientación y episodios (cantidad, orden y grado de completitud); y 10 para medir el contenido: relaciones causales, temporales, espaciales y de cohesión léxica; organización morfosintáctica y referencialidad narrativa. Esta última abarca adecuación semántica y descontextualización. El registro se realiza marcando el número de la conducta o elemento observado, según el ítem o categoría evaluada.

\section{Estructura del cuento}

El cuento construido para evaluar la re-narración tiene una estructura canónica, que corresponde a la clásica división entre "introducción, nudo y desenlace" 0 , en otras palabras "situación o equilibrio inicial", "surgimiento del problema" y "resolución". Presenta una fórmula 
tradicional de inicio (“Había una vez...”), y una coda como cierre (“iEstaba salvada!”). El análisis enfoca los siguientes aspectos:

Ambientación: Aquí se manifiesta el equilibrio inicial. Se registran los datos que responden a las preguntas ¿cuándo? (fórmula de inicio), ¿dónde? (mención del lugar) y ¿quién? (personajes principales y secundarios).

Episodios: Son las partes que constituyen la narración. Para el análisis de la estructura de este cuento, se separa la ambientación (que presenta una acción mínima: "la vio y se acercó") del resto, donde aparecen acciones que hacen avanzar el relato con mayor dinamismo comunicativo. El primer episodio de análisis es el hecho desencadenante, el tercero presenta el problema y el quinto, la resolución.

Secuencia: Se registra específicamente si los episodios son narrados en forma ordenada y completa. Esto implica una macroestructura previa ${ }^{(15)}$ o plan global(16) que organiza el discurso. Se evalúa también el empleo adecuado de los tiempos verbales en el desarrollo del discurso: así como en la Ambientación corresponde el pretérito imperfecto del indicativo, el tiempo que expresa el avance de la acción es el pretérito perfecto simple.

\section{Contenido del cuento}

En el análisis del contenido se observan las relaciones semánticas de cohesión entre las oraciones, necesarias para que éstas constituyan un texto: relaciones causales, temporales, espaciales y léxicas. "La cohesión aparece cuando la interpretación de algún elemento en el discurso depende de la de otro. Uno presupone al otro, en el sentido de que no puede ser efectivamente decodificado sino recurriendo al otro". (24)

Relaciones causales: se analiza la comprensión que manifiesta el niño, del enlace entre causas y efectos en el desarrollo del relato, y cómo lo expresa. Tenemos en cuenta que la causalidad puede expresarse de distintas maneras y no sólo con el conector "porque": la calesita daba vueltas y vueltas hasta que la pelota se mareó. Aquí vemos que "hasta que", temporal, indica la causa del mareo. También la conjunción "y" o el adverbio "entonces" pueden indicar una relación causal, así como la simple yuxtaposición, o los dos puntos, o los correlativos "tan ... que..." con sus variantes de género y número. 
Relaciones espaciales: En el texto de nuestro cuento, las expresiones espaciales son abundantes: verbos de movimiento, preposiciones y frases preposicionales, adverbios y frases adverbiales, referidas al espacio. Por supuesto, no todas las expresiones espaciales se refieren a relaciones de cohesión, sólo aquéllas que resulten imprescindibles para decodificar otro término del texto, generalmente nombrado antes, aunque también puede aparecer después son los "deícticos locativos" (desde ahí, sobre, arriba).

Relaciones léxicas: De las posibles relaciones de cohesión léxica sólo se registra cuantitativamente el uso de los pronombres con antecedente, que tienen función cohesiva.

En cuanto a las repeticiones y elisiones, éstas se registran cualitativamente, ya que su ausencia o presencia no implican habilidad ni dificultad en el desarrollo de una re-narración y, por ende, no justifican puntaje. De todos modos, en los casos en que aparecen, se registra el carácter redundante o no de las repeticiones. En cuanto a las elisiones, cuando tienen antecedente son cohesivas y no lo son cuando no lo tienen.

También se analiza la concordancia y la organización morfosintáctica.

Concordancia: De género y número en las frases nominales; de número y persona en las frases verbales.

Orden sintáctico: Se analiza la adecuación sintáctica, que es inseparable de los niveles semántico y pragmático. El orden de las palabras y la relación entre ellas deciden la claridad y comprensibilidad del enunciado.

La coherencia funciona a nivel conceptual, depende de la intención comunicativa del hablante y se manifiesta gramaticalmente en los mencionados marcadores de cohesión, por lo cual no es necesario que figure como ítem específico ${ }^{(14,25)}$.

Referencialidad: Se analizan dos aspectos, uno vinculado con el eje sintagmático (la compatibilidad de los rasgos semánticos entre los términos empleados) y otro con el eje paradigmático (recuperación léxica).

Asimismo, se tiene en cuenta la capacidad de descontextualizar, es decir, de explicitar verbalmente toda la información necesaria para la comprensión del interlocutor. La incapacidad 
se manifiesta en el uso de deícticos exofóricos, es decir, extratextuales. Por ejemplo, cuando dice "aquí", refiriéndose a un lugar que señala con el dedo en el sitio en que él está y no a uno que acaba de mencionar en su re-narración (deíctico endofórico, cotextual). Por supuesto, se tiene en cuenta que el hecho de compartir información con el evaluador (que vio con él el cuento), puede dificultar la descontextualización, dificultad que disminuye considerablemente con la ausencia de las imágenes durante su re-narración.

Como datos anexos cualitativos, se registra si el niño agrega información nueva y, en este caso, si es pertinente o no. Estos datos están vinculados con el conocimiento que el niño tiene del mundo.

\section{Procedimiento de evaluación}

La evaluación de la re-narración se realiza de la siguiente manera:

Se presenta al niño el cuento "La pelota traviesa", íntegramente grabado en CD (voz e imágenes). Este tipo de presentación obedece a la necesidad de evitar variaciones en la presentación oral del cuento, entre diversos evaluadores y ante cada niño. Se mantienen constantes, así, la naturalidad, el énfasis, la velocidad de lectura, la intensidad de la voz e inteligibilidad.

Se le plantea la consigna: "Ahora te voy a mostrar un cuento que tiene dibujos. Después, tú me lo cuentas a mí". Se le presenta dos veces el cuento. La primera, para introducir al niño en la actividad, que no suele ser habitual; la segunda, para que preste atención al cuento mismo.

Luego, el niño re-narra el cuento sin tener las imágenes a la vista. Consideramos que las imágenes facilitan el recuerdo del ambiente, los personajes y las acciones y le indican la secuencia de los episodios. Por esta razón, preferimos que el niño ya no las tenga a la vista durante su re-narración. Además, le dificultarían la descontextualización porque la historia seguiría presente.

Es fundamental el modo en que el evaluador contribuye a elicitar la re-narración. La consigna se mantendrá idéntica en todos los casos. Durante la actividad, el evaluador puede colaborar con el pie de inicio (Ej. "había una vez...) y luego, puede repetir lo último que dijo el niño, asentir ("¡sí, muy bien!”) o incitarlo a continuar (“¿y entonces?”), sin dar información nueva. Experiencias previas han permitido comprobar que consignas tales como "dime de qué se trata 
la historia" o "¿de qué te acuerdas?" provocan un mal rendimiento en la producción del niño, que no implica fallas reales en sus destrezas narrativas.

La re-narración de niño es grabada para su posterior transcripción y análisis. La transcripción se realiza con la mayor exactitud posible, incluyendo todas las emisiones, pausas, autocorrecciones, latencias, variaciones de entonación, etc. Los datos obtenidos se consignan en el formulario de registro que hemos diseñado a tal efecto, para guiar y ordenar el análisis de modo cuantitativo y cualitativo.

\section{Sujetos}

Este diseño se probó en niños sin trastornos del lenguaje, para disponer de un parámetro de normalidad. Se evaluaron 22 niños preescolares, que concurrían a un jardín de infantes privado de la Ciudad Autónoma de Buenos Aires. Se tomó una sala, al azar, de 25 niños cuya edad oscilaba entre 5.02 y 6.04 . Se excluyeron 3 , de acuerdo con los siguientes criterios: prematuridad (menos de 34 semanas de gestación), bajo peso al nacer (menos de 2000 grs.), estar recibiendo o haber realizado tratamientos o controles por alteraciones neurológicas, sensoriales, psiquiátricas, psicológicas, psicopedagógicas, del lenguaje y/o la comunicación.

Los datos pertinentes se obtuvieron mediante un cuestionario enviado a los padres, y las respuestas correspondientes fueron corroboradas y ampliadas con lo registrado por las maestras, quienes también entregaron información adicional sobre el desempeño de los niños en el ámbito escolar. Participaron de la muestra los niños que alcanzaban los objetivos de sala de 5 años y se ajustaban a los criterios de inclusión.

\section{RESULTADOS}

Con el objetivo de analizar si las variables estudiadas conformaban una estructura subyacente teóricamente significativa, se llevó a cabo el análisis psicométrico de la muestra pilotoii. Se realizó un Análisis de Correlación (Tabla 2), ya que al tratarse de un estudio preliminar con 22 casos, no era posible realizar un Análisis Factorial. Los valores de la estructura y el contenido se obtuvieron mediante la suma de los ítems correspondientes: estructura (ítems $1 \mathrm{a}$ 12); contenido (ítems 13 a 22). (Ver Tabla 1).

ii Resultados presentados en el X Congreso Argentino de Neuropsiquiatría y Neurociencia Cognitiva, organizado por la Asociación Neuropsiquiátrica Argentina, Buenos Aires, septiembre 2008. 
Tabla 1: Correlación estructura-contenido

\begin{tabular}{cccc}
\hline & & Estructura & Contenido \\
\hline \multirow{2}{*}{ Estructura } & Correlación de Pearson & 1 & ${ }^{* *} .608$ \\
\hline Sig. (bilateral) & $N$ & .003 \\
\hline Contenido & Correlación de Pearson & ${ }^{* *} .608$ & 22 \\
\hline & Sig. (bilateral) & .003 & 1 \\
\hline $\mathrm{N}$ & 22 & 22 \\
\hline
\end{tabular}

${ }^{* \star}$ La correlación es significativa al nivel 0,01 (bilateral).

Tabla 2: Análisis de las correlaciones bivariadas entre los ítems

\begin{tabular}{|c|c|c|c|c|c|c|c|c|c|c|c|c|c|c|c|c|c|c|c|c|c|c|}
\hline Ítem & 1 & 2 & 3 & 4 & 5 & 6 & 7 & 8 & 9 & 10 & 11 & 12 & 13 & 14 & 15 & 16 & 17 & 18 & 19 & 20 & 21 & 22 \\
\hline 1 & 1 & & & & & & & & & & & & & & & & & & & & & \\
\hline 2 & $.54^{*}$ & 1 & & & & & & & & & & & & & & & & & & & & \\
\hline 3 & .35 & $.75^{*}$ & 1 & & & & & & & & & & & & & & & & & & & \\
\hline 4 & .42 & .37 & .30 & 1 & & & & & & & & & & & & & & & & & & \\
\hline 5 & .01 & .10 & .28 & .06 & 1 & & & & & & & & & & & & & & & & & \\
\hline 6 & .24 & .40 & .33 & .29 & .34 & 1 & & & & & & & & & & & & & & & & \\
\hline 7 & .19 & .37 & .31 & .25 & $.56^{*}$ & $.46^{*}$ & 1 & & & & & & & & & & & & & & & \\
\hline 8 & -.04 & .06 & .10 & .26 & .34 & .32 & .28 & 1 & & & & & & & & & & & & & & \\
\hline 9 & .07 & .50 & .43 & .15 & .31 & $.67^{*}$ & .34 & .29 & 1 & & & & & & & & & & & & & \\
\hline 10 & .27 & .52 & .25 & .31 & .09 & .40 & .44 & .39 & .49 & 1 & & & & & & & & & & & & \\
\hline 11 & .05 & .42 & $.59^{*}$ & .08 & $.66^{*}$ & $.55^{\star}$ & $.61^{*}$ & .38 & .51 & .46 & 1 & & & & & & & & & & & \\
\hline 12 & .38 & -.01 & -.03 & .01 & .32 & .29 & .12 & .17 & .19 & .37 & .22 & 1 & & & & & & & & & & \\
\hline 13 & .11 & .06 & .06 & .10 & .33 & .26 & .55 & .30 & .17 & .44 & .41 & .45 & 1 & & & & & & & & & \\
\hline 14 & .13 & .32 & .35 & .04 & .42 & .39 & .37 & .34 & $.55^{*}$ & .47 & .45 & .42 & $.67^{*}$ & 1 & & & & & & & & \\
\hline 15 & .07 & -.12 & -.06 & .00 & .45 & $.56^{*}$ & .24 & .32 & .44 & .28 & .27 & $.71^{*}$ & .44 & .50 & 1 & & & & & & & \\
\hline 16 & .03 & .35 & .25 & .19 & .22 & $.73^{*}$ & .49 & .45 & .50 & $.56^{\star}$ & .50 & .23 & .40 & .50 & .37 & 1 & & & & & & \\
\hline 17 & .24 & .08 & .01 & .26 & .29 & .21 & .40 & .40 & .19 & .27 & .18 & .44 & .33 & .21 & .43 & .40 & 1 & & & & & \\
\hline 18 & .25 & .07 & .08 & .33 & .36 & .35 & .37 & .50 & .32 & .33 & .22 & $.60^{*}$ & .41 & .32 & $.62^{*}$ & .41 & $.90^{*}$ & 1 & & & & \\
\hline 19 & .24 & .08 & .01 & .26 & .29 & .21 & .40 & .40 & .19 & .27 & .18 & .44 & .33 & .21 & .43 & .40 & $1^{*}$ & $.90^{*}$ & 1 & & & \\
\hline 20 & .04 & -.15 & -.21 & .02 & .43 & .35 & .47 & .33 & .21 & .22 & .27 & .49 & .40 & .24 & $.68^{*}$ & .43 & $.83^{*}$ & $.73^{*}$ & $.83^{*}$ & 1 & & \\
\hline 21 & .42 & .03 & .09 & .00 & .18 & .14 & .07 & -.20 & .02 & -.13 & -.01 & $.55^{*}$ & .11 & .10 & .44 & .10 & $.54^{*}$ & .45 & $.54^{*}$ & $.54^{*}$ & 1 & \\
\hline 22 & .45 & .47 & .33 & .39 & .09 & .31 & .49 & .16 & .19 & .40 & .27 & .04 & .33 & .15 & .22 & .26 & .51 & .43 & .51 & .37 & .27 & 1 \\
\hline
\end{tabular}

\section{DISCUSIÓN}

Los valores de la competencia del niño concernientes a la estructura y al contenido, resultaron significativamente correlacionados $(r=.61, p=.003)$, lo que indica que los dos aspectos se entrelazan en la adquisición de las destrezas narrativas. 
Destacamos como particularmente importantes las correlaciones entre los siguientes ítems, que resultaron significativas (al nivel 0,01):

Tiempos verbales en los momentos claves del relato con Relaciones espaciales ( $r=.732)$.

Los verbos que hacen avanzar la acción son los que expresan movimiento y, por lo tanto, están directamente vinculados con la espacialidad. Esto cobra importancia, ya que se buscó específicamente que los términos espaciales fueran abundantes en el relato: verbos de movimiento, frases verbales, frases preposicionales y adverbios de lugar (del total de 33 verbos, 15 son espaciales).

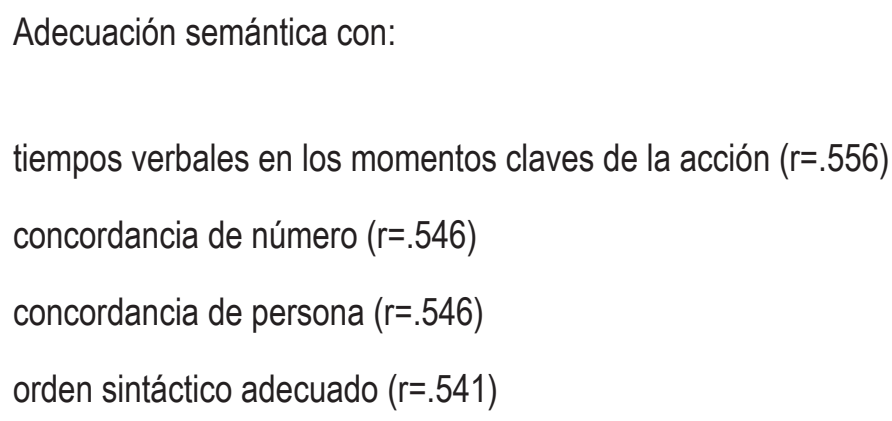

Esto adquiere relevancia, ya que la adecuación semántica depende de la compatibilidad entre los rasgos semánticos de los distintos elementos. Si la adecuación semántica es positiva, entonces el orden sintáctico tiene sentido. Si el instrumento lo detecta, permitirá identificar las fallas, cuando se produzcan.

Ítem 7 (Episodio 3: problema) con Relaciones causales ( $r=.558)$

El peso que tiene la relación causal en las renarraciones de los niños de nuestra muestra, da relevancia a esta correlación. El instrumento permite medir la competencia de cada niño evaluado para comprender la causalidad.

Ítem 7 (Episodio 3: problema) con Ítem 5 (Episodio 1: hecho desencadenante) ( $r=.565)$

Esta correlación indica que en el cuento está claramente planteado el hecho que conducirá al surgimiento del problema. 
Relaciones causales con relaciones temporales ( $r=.672)$.

Esta correlación indica la fortaleza del instrumento para evaluar una relación fundamental en el proceso cognitivo (ver "Importancia de la narración").

\section{CONCLUSIÓN}

Los resultados obtenidos reflejan la fortaleza del instrumento para establecer las destrezas narrativas infantiles en la etapa preescolar, reflejando cuáles son las relaciones que realizan los niños evaluados y entre qué elementos. Estos datos tienen gran significación de modo especial en niños de 5 años, por su valor predictivo del futuro desempeño lingüístico cognitivo en la edad escolar.

Esta confirmación motiva el estudio de una muestra más amplia que permita obtener un perfil representativo de la competencia narrativa en la población en estudio, y de este modo lograr la validez del instrumento y su futura aplicación en la clínica fonoaudiológica con niños con trastornos del lenguaje

Agradecimientos: Agradecemos muy especialmente a la Dra. Cristina Minzi de Richard, Directora del Instituto CIIPME(Centro Interdisciplinario de Investigación de Psicologíay Matemática Experimental), del CONICET, quien nos brindó generosamente su valioso asesoramiento en la realización e interpretación del análisis psicométrico del instrumento.

\section{REFERENCIAS}

1. Abraham, M.V. \& Brenca, R.M. (2002). "El acto de habla en el desarrollo pragmático del lenguaje infantil", Revista Fonoaudiológica, Vol. 48, n², 92-107.

2. Abraham, M.V. \& Brenca, R.M. ( 2005). "Las funciones del lenguaje, sus manifestaciones prelingüísticas y los actos de habla en el niño", en Revista Fonoaudiológica, Vol. 51, n¹, 38-49.

3. Abraham, M.V. \& Brenca, R.M. (2006). "El juego en el ICRA". Revista Fonoaudiológica, Vol. 52 n¹, 21-31.

4. Feagans, L. \& Appelbaum, M. (1986). "Validation of language subtypes in learning disabled children", J Educ Psychol, (78), 358-364.

5. Bishop D.V.M. \& Edmunson, A. (1987). "Language impaired four years olds: Distinguishing transient from persistent impairment". J Speech Hear Disord, 53, 156-173. 
6. Paul, R. \& Smith, R. (1993). "Narrative Skills in 4-Years-Olds with Normal, Impaired, and Late-Developing Language". J Speech Hear Res, 36: 592-598.

7. Pavez, M., Coloma, C., González P., Palma M, S. \& Reinoso N., C. (1999). "El discurso narrativo en niños con trastorno específico del lenguaje". Revista Chilena de Fonoaudiología Año 1, n². 17-32.

8. Wells, G. (1986). The Meaning Makers. Children learning language and using language to learn. Portsmouth, New Hampshire: Heinemann.

9. Barthes, R. (1966). Introduction à l'analyse structurale des récits, en Communications Nro. 8, Paris: Seuil.

10. Bruner, J. (2003), La Fábrica de Historias - Derecho, literatura, vida. Buenos Aires: Fondo de Cultura Económica.

11. Gombert, J. E. (1992). "Metapragmatic Development", en Metalinguistic Development (Cap. V), Chicago: The University of Chicago Press.

12. Schneider, P. (1996). "Effects of pictures versus orally presented stories on story retellings by children with language impairment", Am J Speech Lang Pathol, 5, (1) 86-96.

13. Paul, R.; Hernández, R.; Taylor, L. \& Johnson, K. (1996). "Narrative development in late talkers: early school age". J Speech Hear Res, 39, 1295-1303.

14. Brenca, R.M., (2000). "Comprensión y escritura de los textos científicos", en Intersecciones/ Comunicación, Revista de la Facultad de Ciencias Sociales de la Universidad Nacional del Centro de la Provincia de Buenos Aires, (1, 2da. Época), 71-86.

15. Van Dijk, T. (1980). Estructuras y funciones del discurso. México: Siglo Veintiuno Edit. S.A.

16. Bernárdez, E. (1982). Introducción a la Lingüistica del Texto, Madrid: Espasa-Calpe S.A.

17. Britton, J. (1983). "Writing and the story world", en B.M. Kroll y C.G. Wells (eds.) "Explorations in the Development of Writing", Chichester, Sussex: Wiley.

18. Kant, E. (1942). Crítica de la Razón Pura. Buenos Aires: Editorial Sopena Argentina.

19. Mandler, J. (1999). "Preverbal Representation and Language", en Bloom, Peterson, Nadel y Garrett (eds.). Language and Space, Massachusetts Institute of Technology, Cap. 9.

20. Bruner, J. (2001). Realidad mental y mundos posibles. Cap. IV. Barcelona: Gedisa S.A.

21. Glbbons, J.; Anderson, D. R.; Smith, R.; Field, D. E. \& Fischer, C. (1986). "Young children's recall and reconstruction of audio and audiovisual narratives". Child Dev, (57), 1014-1023. 
22. Hayes, D.S.; Kelly, S. B. \& Mandel, M. (1986). "Media differences in children's story synopses: Radio and television contrasted". J Educ Psychol, (78), 341-346.

23. Renfrew, C. (1977). The bus story language test: A test of continuous speech, en Paul, R. \& Smith, R. (1993). "Narrative Skills in 4-Years-Olds with Normal, Impaired, and Late-Developing Language". J Speech Hear Res, 36: 592-598.

24. Halliday \& Hassan, (1978). Grammatical Cohesion in Spoken and Written English. Londres: Longman.

25. Van Dijk, T. \& Kintsch, W. (1983). Strategies of Discourse Comprehension. San Diego: Academic Press, Inc.

Recibido : Septiembre 2008

Aceptado : Junio 2009 
ANEXO 1

Cuento: "La pelota traviesa"

(Texto: Abraham, M. y Brenca, R.; ilustraciones: Marina Friszman)

1.- Había una vez una pelota traviesa que estaba aburrida en la plaza, sin saber qué hacer. Juan, que venía con su amigo, la vio y se acercó.

2- Entonces, Juan pateó la pelota porque quería jugar un rato, pero ella aprovechó para salir volando por el aire.

3.- Desde arriba, la pelota vio una calesita, que tenía un avioncito. ¡Qué ganas de dar una vuelta!

4.- Se tiró sobre el avioncito porque era rojo y le pareció muy lindo. ¡Qué divertido!

5.- La calesita daba vueltas y vueltas hasta que la pelota se mareó.

¡Quería bajar y no podia! ¡Qué susto!

6.- Entonces, la pelota traviesa dio un salto y, rebotando, muerta de miedo, fue a parar a las ramas de un árbol.

7- De pronto, desde ahí, vio a Juan, que la estaba buscando. La pelota saltó de alegría.

8.- Juan la agarró en el aire y la abrazó tan fuerte que ella casi casi se desinfla de la emoción. ¡Estaba salvada! 


\section{ANEXO 2}

Hoja de registro de la re-narración de "La pelota traviesa"

Nombre del niño:

Edad:

Fecha de nacimiento: $. . / \ldots \ldots \ldots . . . . \ldots \ldots \ldots$

Fecha de evaluación: $\mid \ldots \ldots \ldots \ldots \ldots$

\begin{tabular}{|c|c|c|}
\hline \multicolumn{2}{|c|}{ Estructura } & Puntaje \\
\hline \multicolumn{3}{|l|}{ Ambientación (equilibrio inicial) } \\
\hline \multicolumn{3}{|l|}{ Situación inicial: (Pret. Imp. de Indicativo) } \\
\hline 1) "Había una vez una pelota que estaba aburrida" & $\ldots \ldots \ldots \ldots \ldots \ldots \ldots . . . .($ ausente/incompleta/completa) & $1 / 2 / 3$ \\
\hline \multicolumn{3}{|l|}{ Personajes principales: } \\
\hline 2) "La pelota" - "Juan" & (ninguno/alguno/todos) & $1 / 2 / 3$ \\
\hline \multicolumn{3}{|l|}{ Personaje secundario: } \\
\hline 3) "el amigo de Juan" & $\ldots \ldots \ldots \ldots \ldots \ldots \ldots \ldots \ldots . . .($ (presente/ausente) & $1 / 3$ \\
\hline \multicolumn{3}{|l|}{ Lugar: } \\
\hline 4) "la plaza” & 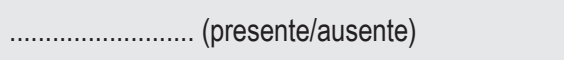 & $1 / 3$ \\
\hline \multicolumn{2}{|c|}{ Puntaje parcial } & $\ldots / 12$ \\
\hline \multicolumn{3}{|l|}{ Episodios } \\
\hline \multicolumn{3}{|l|}{ Hecho desencadenante (Pret. perfecto simple). } \\
\hline 5) "Juan pateó la pelota y ella salió volando" & ........................ (ausente/incompleto/completo) & $1 / 2 / 3$ \\
\hline \multicolumn{3}{|l|}{ Avance de la acción (Pret. perfecto simple). } \\
\hline 6) "La pelota vio una calesita y se tiró sobre el avión rojo" & 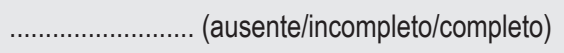 & $1 / 2 / 3$ \\
\hline \multicolumn{3}{|l|}{ Problema (Pret. imperfecto de indicativo). } \\
\hline 7) "La pelota se mareó y no podía bajar" & ....................... (ausente/incompleto/completo) & $1 / 2 / 3$ \\
\hline 8) "La pelota saltó a las ramas de un árbol y vio a Juan" & $\ldots \ldots \ldots \ldots \ldots \ldots . . . .($ ausente/incompleto/completo) & $1 / 2 / 3$ \\
\hline \multicolumn{3}{|l|}{ Resolución (Pret. perfecto simple). } \\
\hline & $\ldots \ldots \ldots \ldots \ldots \ldots . . . .($ ausente/incompleto/completo) & $1 / 2 / 3$ \\
\hline \multicolumn{2}{|c|}{ Puntaje parcial } & $\ldots / 15$ \\
\hline \multicolumn{3}{|l|}{ Secuencia : } \\
\hline \multicolumn{3}{|l|}{ Relación de los episodios } \\
\hline \multicolumn{2}{|l|}{ 10) …………......... (desordenada/ordenada) } & $1 / 3$ \\
\hline \multicolumn{2}{|l|}{ 11) ……................. (incompleta/completa) } & $1 / 3$ \\
\hline $\begin{array}{l}\text { Empleo adecuado de los tiempos verbales en el co } \\
\text { 12) ......................... (en ningún caso / en algún caso / } \\
\text { Situación inicial (pretérito imperfecto de indicativo: hab } \\
\text { Hecho desencadenante (pretérito perfecto simple: pate } \\
\text { Avance de la acción (pretérito perfecto simple: aprovec } \\
\text { Problema (pretérito imperfecto de indicativo: daba vuel } \\
\text { Resolución (pretérito perfecto simple: agarró, abrazó). }\end{array}$ & $\begin{array}{l}\text { texto del discurso: } \\
\text { n todos los casos) } \\
\text {, estaba) } \\
\text { ó, se tiró, dio un salto, fue a parar a, saltó) } \\
\text { s; quería bajar; no podía). }\end{array}$ & $1 / 2 / 3$ \\
\hline \multicolumn{2}{|c|}{ Puntaje parcial } & $\ldots / 9$ \\
\hline \multicolumn{2}{|c|}{ Puntaje total de la Estructura } & $\ldots / 36$ \\
\hline
\end{tabular}




\begin{tabular}{|c|c|c|}
\hline & Contenido & Puntaje \\
\hline \multicolumn{3}{|l|}{ Cohesión-Coherencia } \\
\hline 13) Relaciones causales & . (nunca/a veces/siempre) & $1 / 2 / 3$ \\
\hline 14) Relaciones temporales & $\ldots \ldots \ldots \ldots \ldots \ldots . . .($ nunca/a veces/siempre) & $1 / 2 / 3$ \\
\hline 15) Relaciones espaciales & (nunca/a veces /siempre) & $1 / 2 / 3$ \\
\hline 16) Relaciones de cohesión léxic & (nunca/a veces /siempre) & $1 / 2 / 3$ \\
\hline \multicolumn{3}{|l|}{ a) Pronombres } \\
\hline \multicolumn{3}{|l|}{ - con antecedente } \\
\hline \multicolumn{3}{|l|}{ b) Repeticiones (tildar) } \\
\hline \multicolumn{3}{|l|}{ - cohesivas (no redundante) } \\
\hline \multicolumn{3}{|l|}{ - no cohesivas (redundante) } \\
\hline \multicolumn{3}{|l|}{ c) Elisión (tildar) } \\
\hline \multicolumn{3}{|l|}{ - cohesivas (con antecedente) } \\
\hline \multicolumn{3}{|c|}{ - no cohesivas (sin antecedente) } \\
\hline \multicolumn{3}{|c|}{ Organización morfo-sintáctica adecuada } \\
\hline \multicolumn{3}{|l|}{ a) Concordancia: } \\
\hline 17) número & ........................ (nunca/a veces/siempre) & $1 / 2 / 3$ \\
\hline 18) género & $\ldots \ldots \ldots \ldots \ldots \ldots . . .($ nunca/a veces/siempre) & $1 / 2 / 3$ \\
\hline 19) persona & 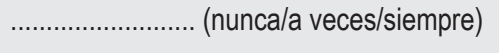 & $1 / 2 / 3$ \\
\hline 20) Orden sintáctico adecuado & $\ldots \ldots \ldots \ldots . . . .($ nunca/a veces/siempre) & $1 / 2 / 3$ \\
\hline \multicolumn{3}{|l|}{ Referencialidad } \\
\hline 21) Adecuación semántica & ....................... (nunca/a veces/siempre) & $1 / 2 / 3$ \\
\hline 22) Descontextualización & $\ldots \ldots \ldots \ldots \ldots \ldots \ldots \ldots . . .($ nunca/a veces/siempre) & $1 / 2 / 3$ \\
\hline \multicolumn{2}{|r|}{ Puntaje total del Contenido } & $\ldots / 30$ \\
\hline \multicolumn{3}{|l|}{ Datos anexos (tildar) } \\
\hline \multicolumn{3}{|l|}{ Información nueva } \\
\hline \multicolumn{3}{|l|}{ - pertinente } \\
\hline \multicolumn{3}{|l|}{ - no pertinente } \\
\hline & Puntaje total & $\ldots / 66$ \\
\hline
\end{tabular}

Observaciones: 